\title{
Relationship between the water molecules in fish-meat gel and the gel structure
}

\author{
Lujia Luo $\cdot$ Yuri Tashiro $\cdot$ Hiroo Ogawa
}

Received: 27 April 2012/Accepted: 11 July 2012/Published online: 15 August 2012

(C) The Author(s) 2012. This article is published with open access at Springerlink.com

\begin{abstract}
To elucidate the structure of the network of the water retention mechanism of fish-meat gel, the microscopic relationship between the water content and viscoelasticity was investigated, and the specific surface area $(S)$ where the water molecules are adsorbed was also measured. The gel structures of fish-meat, actomyosin $(\mathrm{AM})$, and myosin (M) were investigated. In the fish-meat gel, as the water content increased, the number of network chains $(v)$ decreased and the molecular weight between the cross-linking points $\left(M_{\mathrm{e}}\right)$ increased. At $10 \%$ salinity and approximately $79 \%$ moisture, $v$ decreased to a minimum and $M_{\mathrm{e}}$ began to increase remarkably. In addition, when the moisture increased to $78 \%, S$ increased about 1.5 times and the elasticity decreased significantly, indicating that this level of water content is the limit for sufficiently forming a gel structure in fish-meat gel. In the AM and M gels, $M_{\mathrm{e}}$ and $S$ were similar to those observed in the fishmeat gels. When the moisture content increased, they also increased, regardless of the salt concentration. This result suggests that the size of the network was enlarged or that the network chains were cleaved.
\end{abstract}

Keywords Actomyosin - Cross-linking · Fish-meat gel · Molecular weight $\cdot$ Myosin $\cdot$ Network $\cdot$ Rheology · Specific surface area

L. Luo $\cdot$ Y. Tashiro $\cdot$ H. Ogawa $(\varangle)$

Department of Food Science and Technology,

Tokyo University of Marine Science and Technology,

Minato, Tokyo 108-8477, Japan

e-mail: ogawahi@kaiyodai.ac.jp

L. Luo

e-mail: luolujia1984@yahoo.co.jp

\section{Introduction}

Most foods derived from organisms such as plants and animals contain water. While the amount of water can range from just a few percent to more than $90 \%$, it is typically retained in the food and interacts in some manner with food materials. In addition, the water contained in the food that is directly derived from the organism is unlike usual water, and is believed to be highly structured; For example, fish-meat gel (kamaboko), which is made from fish paste, can contain a large quantity of water. Because there are many polymers in a cell or a gel, it is suggested that there are interactions between the water and polymers in the gel [1].

The main polymers in food are glucides, proteins, and lipids, which are composed of monosaccharide, amino acid, and fatty acid units. These units maintain the primary structure of the polymer, and it appears that hydration leads to the stabilization of the structure. In proteins, for example, hydration helps maintain a coiled structure and protects the proteins from heat denaturation, thus contributing significantly to food texture characteristics [2]. In addition, the polymers found in food have a hydrophobic section, polar groups, and dissociation groups that influence the hydration based on their relative positions and strength/ weakness.

The material in a gel is connected together in such a way that the polymer chains also interact strongly with water. This type of structure, which can retain large quantities of free water in a cavity, is of significant interest, but has not yet been understood sufficiently.

Fish-meat gel is an important traditional food product in Japan, and can contain a large quantity of water. Not only the protein, but also the water is important for its physical properties. Therefore, there is significant interest in 
learning more about its properties. To understand the texture and physical characteristics of fish-meat gel, its rheological properties must be investigated [3]. Rheological properties are mainly governed by molecular mass and molecular conformation [4]. These factors are influenced by concentration, temperature, $\mathrm{pH}$, and ionic strength, among others. With increasing concentration, the hydrodynamic domains of the protein molecules come into contact with each other, and these interactions between the suspended proteins are of paramount importance [4]. Heating decreases the viscosity due to an increase in the kinetic energy, and thus thermal denaturation contributes to the rheology of the protein system [4]. The $\mathrm{pH}$ and ionic strength of macromolecular systems affect its rheological properties by altering the electrostatic charge [5]. Differences in the functional properties of different gels may also derive from inherent factors (protein structure, molecular mass, and amino acid composition) [6, 7]. These differences can be investigated by measuring the rheological behavior of the gels. In fish-meat gel, water accounts for approximately $75 \%$ of the entire material. To understand its rheological properties, not only the protein itself, but also its concentration must be known. Furthermore, the relationship between the water and protein, and how this relationship affects the gel structure and the state of the network chain must also be elucidated.

In the present study, to clarify the water retention mechanism at a molecular level in fish-meat protein gels with various salinities, the number of network chains, the molecular weight between the cross-linking points, the specific surface area, and the rheological properties were measured. The number of network chains and the molecular weight between the cross-linking points were analyzed on the basis of the rubber elasticity theory; For example, because kamaboko exhibits entropy elasticity, Takagi [8] measured the stress-strain behavior at tension and compression sides of kamaboko (without added starch) and compared the stressstrain curve with that of an ideal rubber, and Niwa [9] reported a similar experiment that considered the decrease in the sectional area with pulling. In addition, Hamada [10] examined the factors for temperature changes in kamaboko when it is stretched, and reported that the stress-strain curve of kamaboko was similar to that of an ideal rubber, but only when assuming that the elasticity of kamaboko is not just entropy elasticity but also energy elasticity. However, at approximately $25{ }^{\circ} \mathrm{C}$, it has been reported that entropy elasticity contributes more to the elasticity of kamaboko, and that its elasticity is basically entropy elasticity. Therefore, in the present study, the viscoelasticity of kamaboko was considered to be rubber elasticity.

In fact, the myofibrillar proteins actomyosin (AM) and myosin $(\mathrm{M})$, which are the major proteins responsible for gelation, play an important role in determining the texture and processing characteristics of meat products. The myofibrillar proteins are generally extracted in an intermediate- or highionic-strength buffer, and are therefore referred to as saltsoluble proteins. They constitute approximately $55-60 \%$ of the total muscle protein or $10 \%$ of the weight of skeletal muscle [7]. The heat-induced gelation of $M$ results in the formation of a three-dimensional (3D) network structure that holds water in a less mobile state [11]. It has been suggested that the rheological and physical properties of $\mathrm{M}$ gels are more dependent upon molecular size and less influenced by the amino acid composition or distribution [12]. During network formation, water retention is enhanced, which influences the yield, texture, and cohesion of the final product, and also determines the gelling capacity of the myofibrillar proteins [13]. However, the aggregation of the protein can also affect the physical properties of the network, and when heated, it just coheres rather than forming a gel, thus not reflecting the elasticity but only the hardness of the gel. It also interacts with $\mathrm{M}$ directly or indirectly and thus influences the $\mathrm{M}$ gel, so consideration of the characterization of kamaboko as a rubber is not very scientific. Therefore, to correctly and clearly understand the gel structure, the salt-soluble protein was extracted and used to prepare a simple network. Consequently, in this study, AM and M gels were also prepared with different water contents to determine their structures and compare their characteristics with those of the fish-meat protein gels.

\section{Materials and methods}

\section{Fish-meat gel preparation}

Sample gels were prepared from frozen surimi (SA grade) of Alaska pollack Theragra chalcogramma, which was stored at $-20{ }^{\circ} \mathrm{C}$ and then partially thawed at $5{ }^{\circ} \mathrm{C}$ for one night. Approximately $200 \mathrm{~g}$ surimi was cut into small pieces by chopping with a cutter for $2 \mathrm{~min}$. The chopped material was mixed for 2 min with enough $\mathrm{NaCl}$ and distilled water to create final formulations with $76,77,78,79$, 80 , and $81 \%$ water content and with salinities of 5 and $10 \%$. These materials defined as sols were maintained at temperature below $5{ }^{\circ} \mathrm{C}$. To obtain the cooked gels, the sol was placed into polyvinyl chloride casings $(d=2 \times$ $10^{-2} \mathrm{~m}$ ) and subjected to heating at $80{ }^{\circ} \mathrm{C}$ for $30 \mathrm{~min}$ in a water bath. These gels were cooled in ice water for $10 \mathrm{~min}$ and then stored at $4{ }^{\circ} \mathrm{C}$ until analysis.

\section{$\mathrm{M}$ and $\mathrm{AM}$ gel preparation}

Alaska pollack M was prepared [14] as follows: First, frozen surimi was cut into small pieces, and a fivefold volume of $50 \mathrm{mM}$ phosphate buffer ( $\mathrm{pH}$ 7.0) was used to 
wash the material three times, with the pellets collected each time using a gauze. Then, the pellets were mixed with a threefold volume of $0.45 \mathrm{M} \mathrm{KCl}, 17.6 \mathrm{mM} \mathrm{Na}_{2} \mathrm{HPO}_{4}$, $49 \mathrm{mM} \mathrm{KH}{ }_{2} \mathrm{PO}_{4}, 10 \mathrm{mM} \mathrm{Na}{ }_{4} \mathrm{P}_{2} \mathrm{O}_{7}(\mathrm{pH}$ 6.4) for 7 min to extract the M. Next, the mixture was subjected to centrifugation at $10000 \times g$ for $15 \mathrm{~min}$ to remove the precipitates. The supernatant was then added to 10.3 times the volume of cold distilled water. The precipitate was again collected by centrifugation at $10000 \times g$ for $10 \mathrm{~min}$ and then washed with a fivefold volume of $0.03 \mathrm{M} \mathrm{KCl}$ and $10 \mathrm{mM}$ Trismaleate ( $\mathrm{pH}$ 7.5). The precipitate was obtained after centrifugation at $10000 \times g$ for $10 \mathrm{~min}$. Then the precipitate was washed again, and AM was obtained after centrifugation at $10000 \times g$ for $10 \mathrm{~min}$. AM was then dissociated into actin and $\mathrm{M}$ using $3 \mathrm{M} \mathrm{KCl}, 80 \mathrm{mM}$ Tris-maleate $(\mathrm{pH}$ 7.5), $0.6 \mathrm{M} \mathrm{KCl}, 50 \mathrm{mM} \mathrm{Na}{ }_{4} \mathrm{P}_{2} \mathrm{O}_{7}$ (pH 7.5), $1 \mathrm{M} \mathrm{MgCl}_{2}$, $0.1 \mathrm{M}$ ethylenediamine tetraacetic acid (EDTA), $50 \mathrm{mM}$ 2-mercaptoethanol, $0.6 \mathrm{M} \mathrm{KCl}, 10 \mathrm{mM}$ Tris-maleate $(\mathrm{pH}$ 7.5) with gentle stirring for one night, followed by addition of $5 \mathrm{mM}$ adenosine triphosphate (ATP) and the removal of the actin by ultracentrifugation at $100000 \times g$ for $1 \mathrm{~h}$. The supernatant was diluted with a sixfold volume of $0.05 \mathrm{M}$ $\mathrm{NaCl}, 20 \mathrm{mM}$ phosphate buffer (pH 7.0), and the precipitated $\mathrm{M}$ was collected by centrifugation at $10000 \times \mathrm{g}$ for 10 min. The $\mathrm{AM}$ and $\mathrm{M}$ were mixed with $\mathrm{NaCl}$ and distilled water to prepare solutions with final concentrations of $89,90,91,92$, and $93 \%$ moisture and salinities of 5 and $10 \%$. The solutions were then heated at $80{ }^{\circ} \mathrm{C}$ for $30 \mathrm{~min}$ in a water bath to obtain the cooked gels. These gels were cooled in ice water for $10 \mathrm{~min}$ and then stored at $4{ }^{\circ} \mathrm{C}$ until analysis.

\section{SDS-PAGE}

To confirm that the $\mathrm{AM}$ and $\mathrm{M}$ were indeed isolated, sodium dodecyl sulfate-polyacrylamide gel electrophoresis (SDS-PAGE) was carried out on a slab gel electrophoresis device (KS-8001; Oriental Instruments LTD, Japan) using commercially supplied PhastGel. The thickness of the gel was approximately $1 \mathrm{~mm}$. The sample buffer used for electrophoresis was composed of $25 \% 0.5 \mathrm{M}$ Tris-HCl (pH 6.8), $20 \%$ glycerin, $4 \%$ sodium dodecyl sulfate (SDS), $0.01 \%$ bromophenol blue (BPB), and $10 \%$ 2-mercaptoethanol in $100 \mathrm{ml}$ distilled water. Soluble protein were mixed $(1: 1, \mathrm{v} / \mathrm{v})$ with the sample buffer. Immediately following the electrophoresis run at $20-25 \mathrm{~mA}$, the gels were removed from the unit and placed in a development unit for staining. The staining solution was composed of $0.25 \%$ CBB R-250 in $50 \%$ methanol and $10 \%$ acetic acid in distilled water. After 30-60 min, the gels were then treated with a destaining solution composed of $30 \%$ methanol and $10 \%$ acetic acid in distilled water. The destaining solution was changed every $15-20$ min until several bands were observed. These bands were used to confirm whether AM and M were extracted.

Salt-soluble proteins

Muscle protein can be classified on the basis of its solubility in salt. The protein forming the elasticity of kamaboko is the myofibril protein, which is a salt-soluble protein. The Lowry method [15] was used to determine the protein concentration. Protein solutions of 2.5, 5, and $10 \%$ salinity were prepared, and the concentrations were measured by absorbance (ABS) at $750 \mathrm{~nm}$. In this study, a spectrophotometer (U-3300; Hitachi Ltd., Tokyo Japan) was used to confirm the relationship between the salinity and the quantity of salt-soluble protein. Water was used as the reference.

\section{Stress-relaxation measurements}

Kamaboko gels were heated at each temperature $(15,25$, 35 , and $45^{\circ} \mathrm{C}$ ), and the temperature was maintained during the texture measurement using a rheometer (Tensipressor, TTP-50BXII; Taketomo Elect.). The gels were cut into pieces (length $1.0 \times 10^{-2} \mathrm{~m}$ ), and $7-10$ pieces were placed into a tray for each measurement. A cylindrical plunger with diameter of $1.2 \times 10^{-2} \mathrm{~mm}$ was used, and the plunge rate was $2 \times 10^{-3} \mathrm{~m} / \mathrm{s}$. The compression time for the measurement was $60 \mathrm{~s}$, and the strain was 0.1 .

\section{Dynamic viscoelasticity measurements}

An RS 50 Haake Rheostress instrument was used to characterize the rheological behavior of kamaboko, AM, and $\mathrm{M}$ gels. The two main parameters determined in a dynamic rheological test are the storage modulus, $G^{\prime}$, and the loss modulus, $G$ ". All the dynamic rheological measurements were obtained at frequency of $1 \mathrm{~Hz}$, the temperature was increased at a rate of $1^{\circ} \mathrm{C} / \mathrm{min}$, and the thickness of the samples was $1 \times 10^{-3} \mathrm{~m}$. A plate and plate sensor system (PP35) was used for the measurement compartment, and it was heated to $10-80{ }^{\circ} \mathrm{C}$ to measure the storage modulus, $G^{\prime}$. To prevent evaporation, deionized water was spread over the outer edges of the sample.

\section{Specific surface area}

It is thought that the molecule-specific surface area of the fish-meat protein gel reflects the area that exists between the cross-linking points of the gel. Therefore, the specific surface area as determined by the Brunauer-EmmettTeller (BET) method [16] can be used to evaluate the structure of protein gel. Consequently, by measuring the specific surface area of the gel where water molecules are 
adsorbed, the relationships between the moisture or salt content and the molecule-specific surface area can be examined at a molecular level.

The sample gels were prepared as described above. Gels with different moisture contents were dried for 2 weeks below $30{ }^{\circ} \mathrm{C}$ and then powdered. The powdered samples were passed through a stainless-steel sieve (JIS Z 8801) to select particles with diameter of 100-106 $\mu \mathrm{m}$. The specific surface area was measured by the BET method with a Kinoshita-type surface area apparatus (KR-300; Kinoshita RKC Instrument Co., Ltd.). Approximately 0.1-0.2 g dried and graded powder was placed in a flask, and the flask was then connected to the device. An oil diffusion pump was used to degas the system until a vacuum of $1.33 \times 10^{-2}$ to $1.33 \times 10^{-3} \mathrm{~Pa}$ was reached. In addition, the sample was heated and vacuated to remove the water as vapor. Next, only the flask with samples was soaked in a Dewar bottle filled with liquid nitrogen. Then, first, only helium gas was led into the flask to evaluate the dead surface area of the system, because helium with boiling point of ca. $4 \mathrm{~K}$, lower than that (ca. $77 \mathrm{~K}$ ) of nitrogen, shows no adsorption on the sample surface, and the resulting change in pressure could be read on the burette. Second, only argon gas, with boiling point ca. $87 \mathrm{~K}$ higher than that of nitrogen, was substituted for the helium to adsorb on the sample surface, and the pressure was again read on the burette. The quantity of adsorbed gas was calculated by subtracting the amount of helium adsorbed from that of argon adsorbed. In addition, because the measurement was carried out at $20^{\circ} \mathrm{C}$, the time for the gas to be adsorbed by the sample was considered to be the adsorption equilibrium time, and was within $5 \mathrm{~min}$.

\section{Statistical analysis}

Statistical analysis was performed using Excel and Statistical Analysis System software (SAS Institute Inc., Cary, NC). Significant difference were defined at $p<0.05$. Comparison of means was carried out by Duncan's multiple-range test.

\section{Results}

\section{Salt-soluble proteins}

Based on a standard curve made using bovine serum albumin, the quantity of salt-soluble protein per $10 \mathrm{~g}$ sol was calculated from the ABS of the sample. The quantity of salt-soluble protein in the fish gel with salt content of $5 \%$ was $102 \mathrm{mg}$, and in the gel with salt content of $10 \%$ was $109 \mathrm{mg}(p<0.05)$. The gel with salt content of $2.5 \%$ contained $76 \mathrm{mg}$ salt-soluble protein per $10 \mathrm{~g}$ sol (Table 1).
Table 1 Quantity of salt-soluble protein in the fish at different salt concentrations

\begin{tabular}{lc}
\hline Salt-soluble protein $(\mathrm{mg} / \mathrm{sol} 10 \mathrm{~g})$ & Salt concentration $(\%)$ \\
\hline $76 \pm 1.37^{\mathrm{z}}$ & 2.5 \\
$102 \pm 1.02^{\mathrm{y}}$ & 5.0 \\
$109 \pm 1.21^{\mathrm{x}}$ & 10.0 \\
\hline
\end{tabular}

Different letters in the same column indicate significant differences $(p<0.05)$
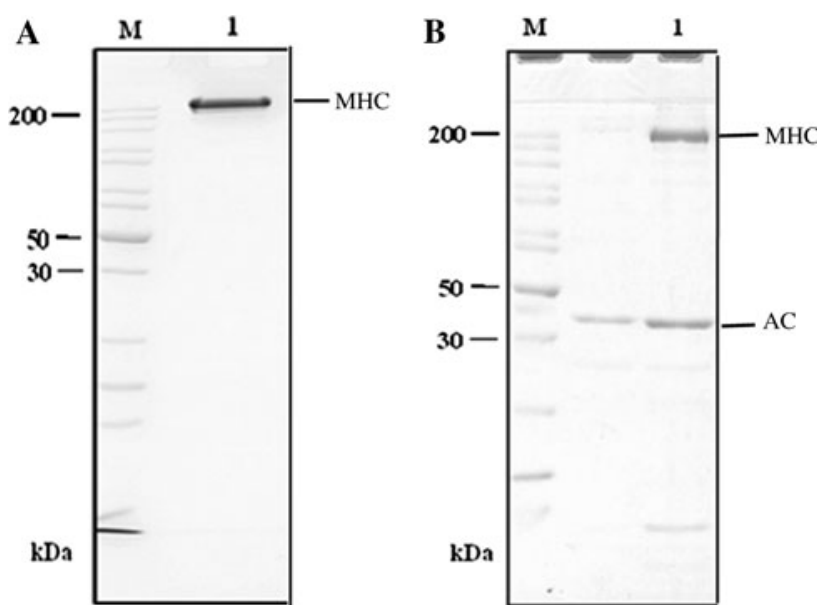

Fig. 1 SDS-PAGE of myofibrillar protein (a myosin, b actomyosin, $m$ standard proteins, Lane 1 loaded with $10 \mu \mathrm{g}$ protein on $12 \%$ SDSPAGE, $M H C$ myosin heavy chain, $A C$ actin)

As can be seen from these results, the amount of saltsoluble protein increased remarkably when the salt content increased to $5 \%$, but did not increase noticeably when the salt content exceeded $5 \%$.

Muscle $\mathrm{M}$, the main component of the myofibrillar proteins, is composed of two heavy chains of approximately $220 \mathrm{kDa}$ each, and four light chains of approximately $20 \mathrm{kDa}$ each [17]. M's heavy chain is composed of a long $\alpha$-helix tail and a globular head. The two heavy chains are woven together to form a tail and two pearshaped heads [18]. Actin is about $42 \mathrm{kDa}$. From the results of the SDS-PAGE analysis, it was confirmed that actin and $\mathrm{M}$ were isolated from the surimi (Fig. 1). As with the fishmeat gel, the quantity of $\mathrm{M}$ and $\mathrm{AM}$ in the corresponding gels with different salt contents did not change significantly. At salt contents of 5 and $10 \%$, the $\mathrm{M}$ and AM concentrations were 0.12 and 0.15 , and 0.26 and $0.33 \mathrm{mg} / \mathrm{ml}$, respectively (Fig. 2). However, the results did indicate that, at the same salt concentrations, the amount of dissolved $\mathrm{M}$ was less than that of dissolved AM.

Number of network chains

The fish paste was affected by changes in temperature, with the result that the elastic modulus changed, and thus it was 


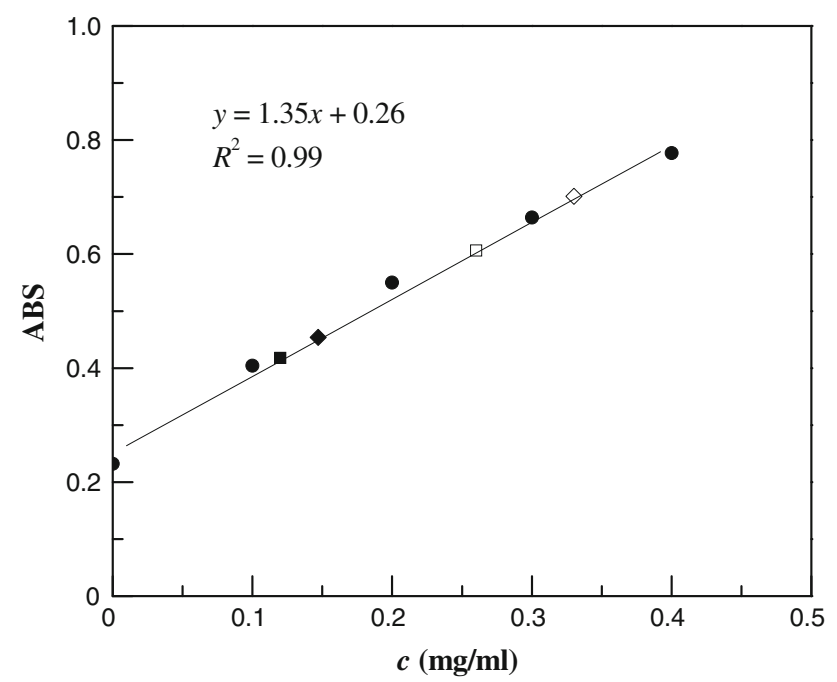

Fig. 2 Standard curve of bovini albumin. Filled circles standard, filled square $5 \% \mathrm{M}$ salted, filled diamond $10 \% \mathrm{M}$ salted, open square $5 \%$ AM salted, open diamond $10 \%$ AM salted

assumed to exhibit entropy elasticity. Therefore, based on the temperature dependence of the elasticity $E_{0}$, the number of chains per unit volume of the sample was determined. By the rubber elastic theory [19], it was found that at each temperature,

$P=v R T\left\{\left(L / L_{\mathrm{u}}\right)^{2}-\left(L_{\mathrm{u}} / L\right)\right\}^{2}$

where $R$ is the gas constant, $v$ is the number of chains per unit volume (mol/l), $T$ is the absolute temperature, $L_{\mathrm{u}}$ is the length of the sample before the transformation $(\mathrm{m}), L$ is the length of the sample after transformation (m), and $P=E_{0}$ is the elastic modulus. $E_{0}$ was obtained as $E_{0}=p_{0} / e_{0}$, where $p_{0}$ is the initial stress and $e_{0}$ is the strain. The values for the elastic modulus of the gels as determined from static viscoelasticity measurement using gels with 5 and $10 \%$ salt contents are shown in Figs. 3 and 4, respectively. From Figs. 3 and 4, it can be seen that, when the moisture content and central temperature of the gel increased, the elastic modulus decreased $(p<0.05)$. The relationship between the number of network chains and the moisture content for the gels with 5 and $10 \%$ salt content at different temperatures is shown in Figs. 5 and 6, respectively. As the moisture in the gel increased, the number of network chains decreased $(p<0.05)$. Therefore, because the concentration of the protein decreased with an increase in the moisture content, the network density that supports the gel structure decreased. At water content of approximately $79 \%$, the number of network chains in the fish-meat gel with $10 \%$ salt content decreased to a noticeably small value $(p<0.05)$. In other words, moisture of approximately $79 \%$ serves as a boundary that prevents sufficient formation of a network structure. In addition, the

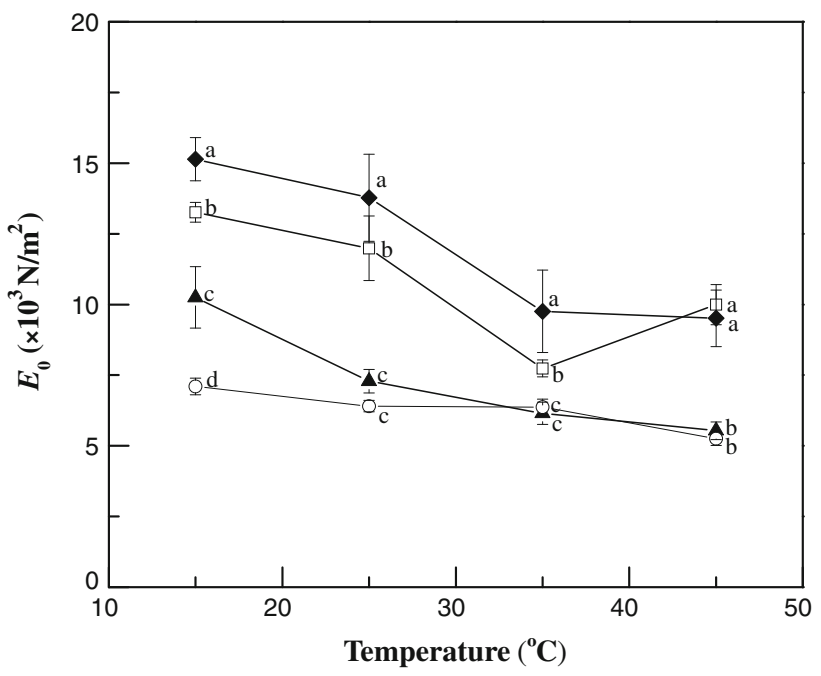

Fig. 3 Elastic modulus at different temperatures of $5 \%$ salt fish gel. Filled diamonds $75 \%$, open squares $77 \%$, filled triangles $79 \%$, open circles $80 \%$. Different letters indicate significant differences $(p<0.05)$

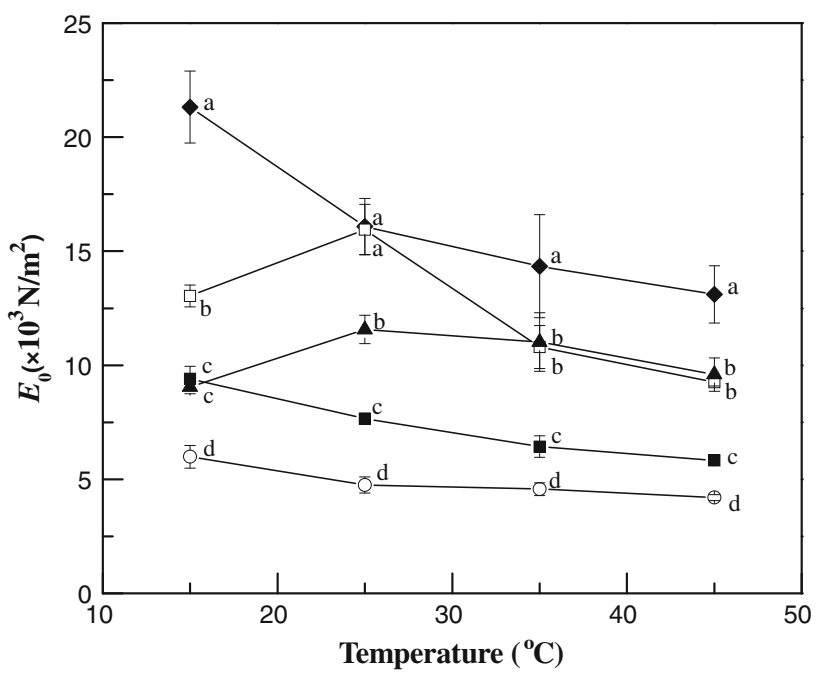

Fig. 4 Elastic modulus at different temperatures of $10 \%$ salt fish gel. Filled diamonds $75 \%$, open squares $77 \%$, filled triangles $78 \%$, open circles $79 \%$, filled squares $80 \%$. Different letters indicate significant differences $(p<0.05)$

temperature influence was important as well: as the temperature increased, the change in the number of network chains decreased.

Molecular weight between the cross-linking points

The average molecular weight between the cross-linking points can be determined from the storage modulus when the network size of the gel has been estimated [20]. The storage modulus results from the vibration of the polymer chains and structures forming aggregation. Therefore, in this study, it was assumed that the entangled points in the 


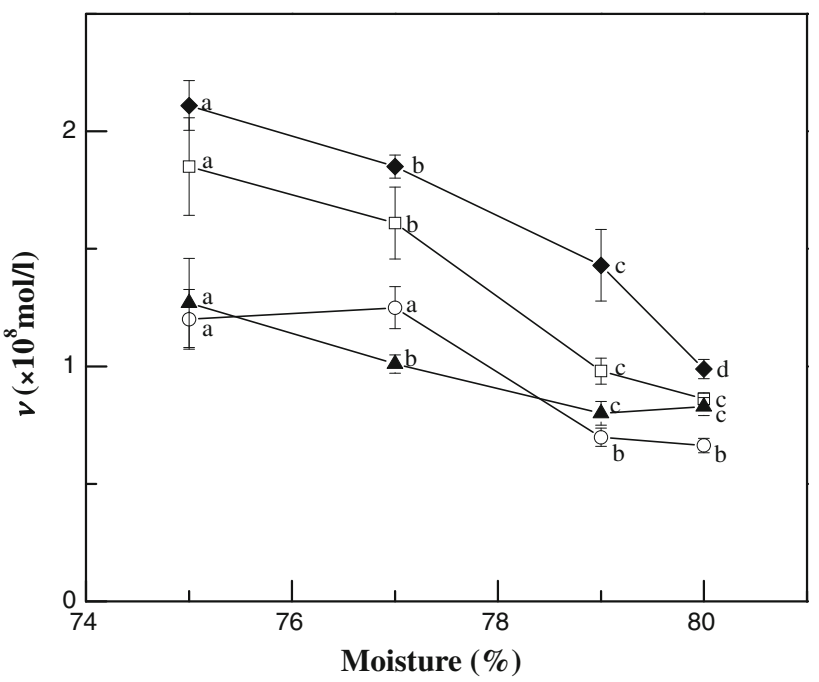

Fig. 5 Relationship between the moisture and the number of network chains at different temperatures in $5 \%$ salt fish gel. Filled diamonds $15{ }^{\circ} \mathrm{C}$, open squares $25^{\circ} \mathrm{C}$, filled triangles $35^{\circ} \mathrm{C}$, open circles $45^{\circ} \mathrm{C}$. Different letters indicate significant differences $(p<0.05)$

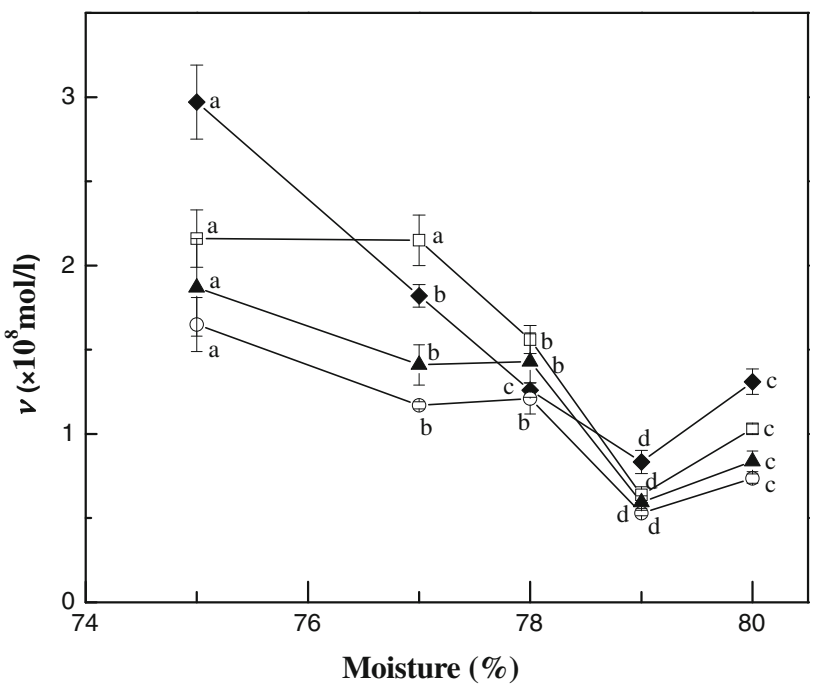

Fig. 6 Relationship between the moisture and the number of network chains at different temperatures in $10 \%$ salt fish gel. Filled diamonds $15{ }^{\circ} \mathrm{C}$, open squares $25^{\circ} \mathrm{C}$, filled triangles $35{ }^{\circ} \mathrm{C}$, open circles $45^{\circ} \mathrm{C}$. Different letters indicate significant differences $(p<0.05)$

fish-meat protein gel behave like cross-linking points, and that the elasticity is due to the storage modulus, which can be determined from dynamic viscoelasticity measurements. Thus, the molecular weight between the cross-linking points could be estimated from the theoretical formula for the rubber-like elasticity in amorphous polymers, as follows:

$G^{\prime}=\rho \varphi^{1 / 3} R T / M_{\mathrm{e}}$
Table 2 Minimum storage elastic modulus and temperature for each water content in $5 \%$ salt gel

\begin{tabular}{lll}
\hline $\begin{array}{l}\text { Water content } \\
(\%)\end{array}$ & $\begin{array}{l}\text { Storage elastic modulus } \\
\left(\times 10^{3} \mathrm{~N} / \mathrm{m}^{2}\right)\end{array}$ & $\begin{array}{l}\text { Temperature } \\
\left({ }^{\circ} \mathrm{C}\right)\end{array}$ \\
\hline 76 & $5.05 \pm 0.03^{\mathrm{a}}$ & $58.8 \pm 1.8$ \\
77 & $4.19 \pm 0.07^{\mathrm{d}}$ & $50.6 \pm 2.3$ \\
78 & $4.75 \pm 0.11^{\mathrm{b}}$ & $56.6 \pm 2.1$ \\
79 & $4.53 \pm 0.07^{\mathrm{c}}$ & $61.2 \pm 1.2$ \\
80 & $3.11 \pm 0.09^{\mathrm{e}}$ & $64.1 \pm 1.5$ \\
81 & $2.40 \pm 0.04^{\mathrm{f}}$ & $55.8 \pm 1.0$ \\
\hline
\end{tabular}

Different letters in the same column indicate significant differences $(p<0.05)$

Table 3 Minimum storage elastic modulus and temperature for each water content in $10 \%$ salt gel

\begin{tabular}{lll}
\hline $\begin{array}{l}\text { Water content } \\
(\%)\end{array}$ & $\begin{array}{l}\text { Storage elastic modulus } \\
\left(\times 10^{3} \mathrm{~N} / \mathrm{m}^{2}\right)\end{array}$ & $\begin{array}{l}\text { Temperature } \\
\left({ }^{\circ} \mathrm{C}\right)\end{array}$ \\
\hline 76 & $5.73 \pm 0.10^{\mathrm{c}}$ & $60.6 \pm 1.1$ \\
77 & $7.25 \pm 0.08^{\mathrm{a}}$ & $57.7 \pm 1.1$ \\
78 & $6.82 \pm 0.09^{\mathrm{b}}$ & $67.2 \pm 1.5$ \\
79 & $4.75 \pm 0.15^{\mathrm{d}}$ & $55.2 \pm 1.7$ \\
80 & $3.87 \pm 0.16^{\mathrm{e}}$ & $63.5 \pm 1.2$ \\
\hline
\end{tabular}

Different letters in the same column indicate significant differences $(p<0.05)$

where $\rho$ is the density $\left(\mathrm{kg} / \mathrm{m}^{3}\right), \varphi$ is the volume fraction of the polymer, $R$ is the gas constant, $T$ is the absolute temperature, and $M_{\mathrm{e}}$ is the molecular weight. The results of the dynamic viscoelasticity measurements are presented in Tables 2 and $3(p<0.05)$. From the data in the tables, it can be seen that the storage modulus of the protein gel decreased when the temperature reached $50-60{ }^{\circ} \mathrm{C}$. It is thought that, as the surimi was heated, the AM in the fishmeat underwent enzyme digestion, resulting in the deterioration of the gel, because at this temperature, the activity of the enzyme protease is at its highest level.

Based on the values in these tables, the average molecular weights between the cross-linking points for the gels with different moisture contents were calculated and are shown in Fig. 7. As the moisture increased, the average molecular weight between the cross-linking points of the gel also increased. When the moisture content increased above $78-79 \%$, the average molecular weight between the cross-linking points increased remarkably $(p<0.05)$.

In the same manner, the average molecular weight between the cross-linking points of the $\mathrm{M}$ and AM gels with various moisture contents were also calculated (Figs. 8, 9). It can be seen from the figures that, as the moisture increased, the average molecular weight between 


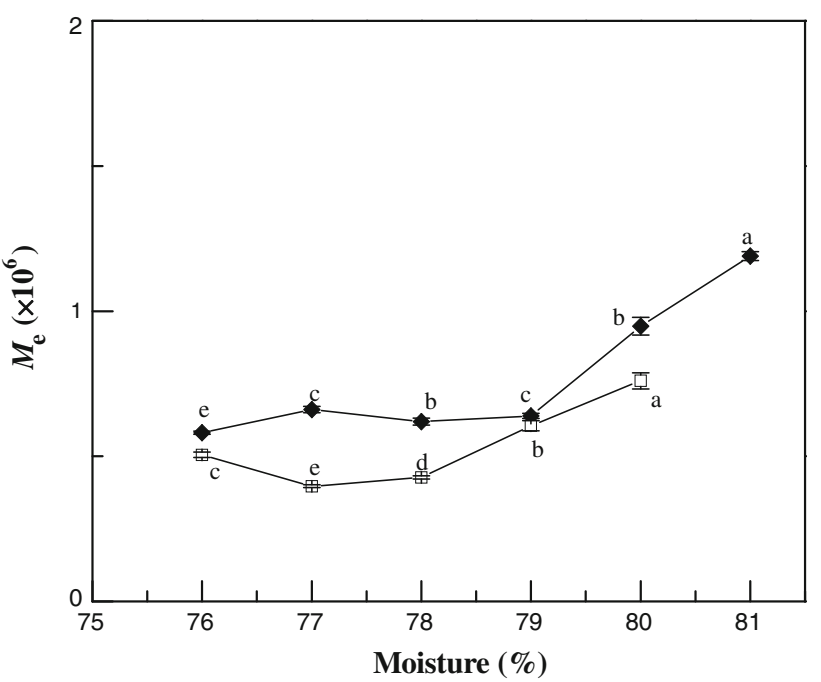

Fig. 7 Relationship between the moisture and the molecular weight between the cross-linking points of fish gels. Filled diamonds $5 \%$ salted, open squares $10 \%$ salted. Different letters indicate significant differences $(p<0.05)$

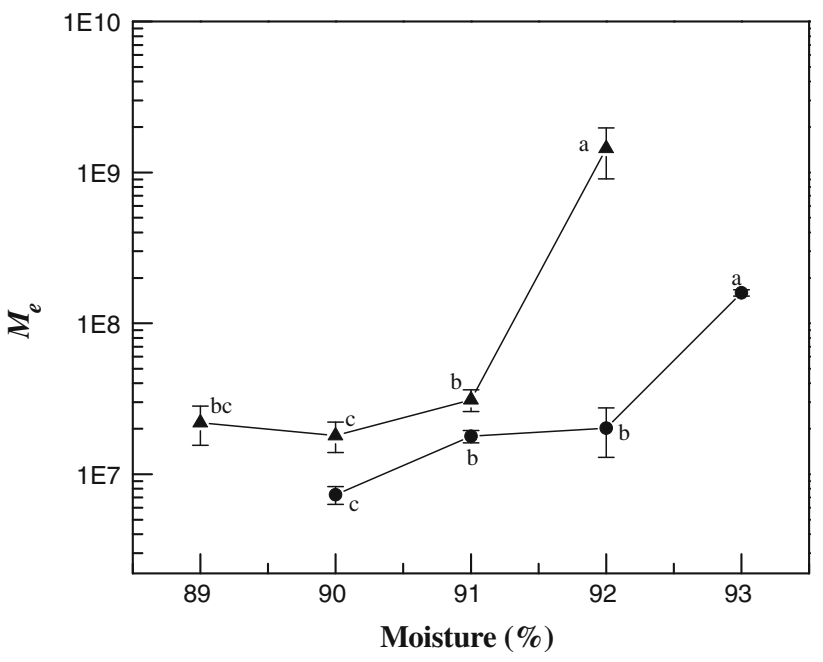

Fig. 8 Relationship between the moisture and the molecular weight between the cross-linking points of myosin gels. Filled triangles $5 \%$ salted, filled circles $10 \%$ salted. Different letters indicate significant differences $(p<0.05)$

the cross-linking points of the $\mathrm{M}$ gel also increased $(p<0.05)$. Specifically, at water content exceeding $91 \%$ and salinity of $5 \%$, the molecular weight between the cross-linking points increased remarkably. This result also indicates that the region within the gel structure increased in size. A similar phenomenon was also observed for the AM gel, but when the moisture content neared $92 \%$, the molecular weight between the cross-linking points decreased, which may be due to the lack of gel formation resulting from low-density cross-linking of AM. In addition, compared with the fish-meat gel, the $\mathrm{M}$ gel had higher

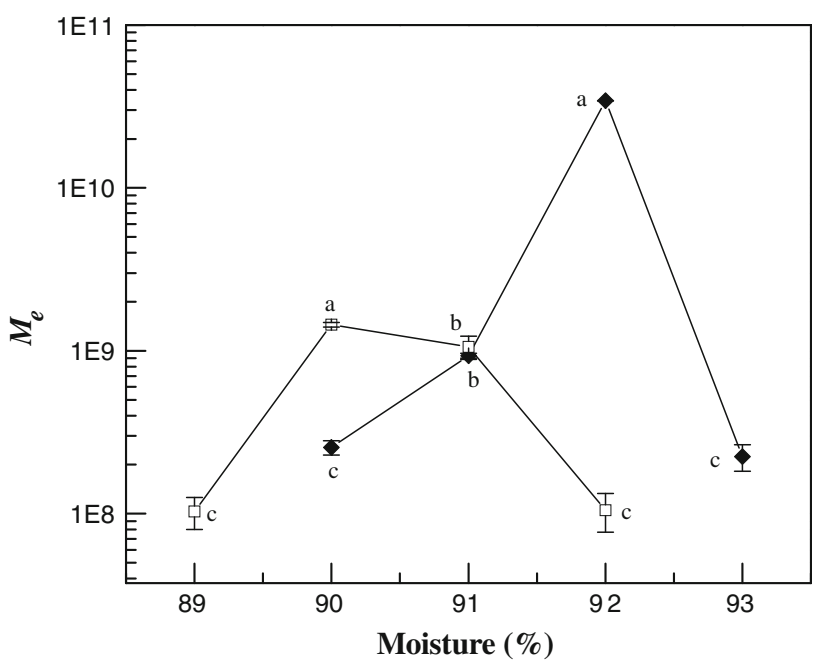

Fig. 9 Relationship between the moisture and the molecular weight between the cross-linking points of actomyosin gels. Filled diamonds $5 \%$ salted, open squares $10 \%$ salted. Different letters indicate significant differences $(p<0.05)$

water retention ability, which indicates that the other proteins do not contribute to the network.

Specific surface area

The BET theory explains the physical adsorption of gas molecules onto a solid surface and serves as the basis for an important analysis technique for the measurement of the specific surface area of a material. The quantity of gas adsorbed as a monolayer on the sample surface can be calculated on the basis of the equation

$P / V\left(P_{0}-P\right)=1 /\left(V_{\mathrm{m}} \times C\right)+(C-1) /\left(V_{\mathrm{m}} \times C\right) \times P / P_{0}$

where $P_{0}$ is the saturation pressure of the adsorbate, $V_{\mathrm{m}}$ is the gas quantity adsorbed by the monolayer, and $C$ is the BET constant. Then, the specific surface area $S$ can be calculated from the results of the amount of gas adsorbed by $1 \mathrm{~g}$ of a sample as

$S=V_{\mathrm{m}} \times N_{A} \times A / V_{0}$

where $S$ is the specific surface area, $N_{\mathrm{A}}$ is Avogadro's number, and $V_{0}$ is the molar volume of the adsorbent gas. The results of the calculation of the specific surface area in the 5 and $10 \%$ salt content gels are shown in Fig. 10. For the gel with salt content of $10 \%$, the specific surface area did increase when the moisture content increased $(p<0.05)$. In particular, when the moisture content increased from 77 to $78 \%$, the specific surface area increased by a factor of approximately 1.5 . However, the specific surface area of fish-meat gel with $80 \%$ water content tended to decrease with increasing water content. It 


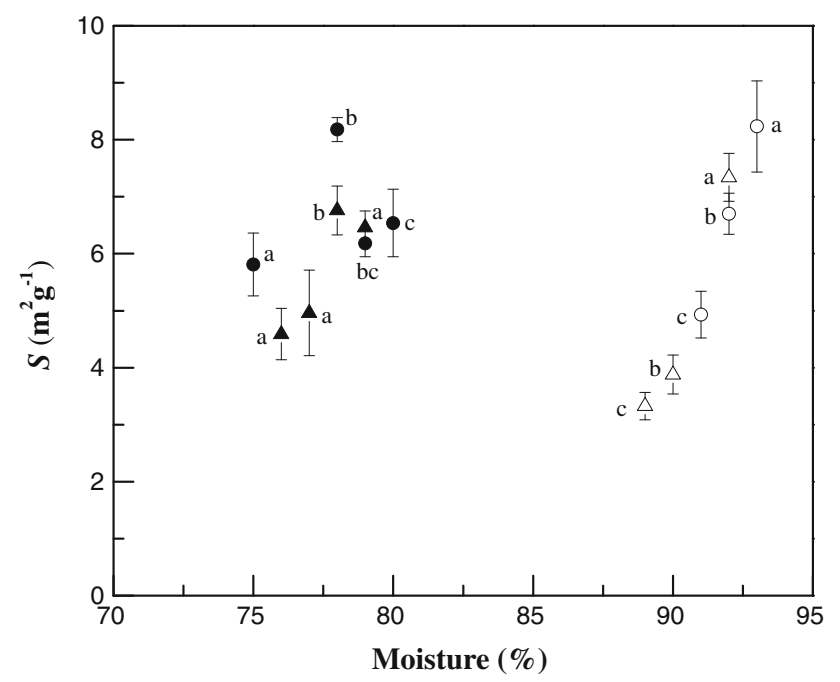

Fig. 10 Relationship between the water-holding ability and the specific surface area of the gel. Filled circles $10 \%$, filled triangles $5 \%$ salted fish gels, open circles $10 \%$ salted myosin gels, open triangles $5 \%$ salted myosin gels. Different letters indicate significant differences $(p<0.05)$

is possible that, as the moisture content increases, the formation of the gel does not sufficiently take place, so that the amount of aggregation is high, and the surface available for the adsorption of water molecules does not grow.

It was also observed that the specific surface areas of the $\mathrm{M}$ increased as the moisture content increased (Fig. 10) $(p<0.05)$. The change in the specific surface area corresponds to the change in the molecular weight between the cross-linking points of the gels, indicating that, when the moisture content increases, the structure of gels changes.

\section{Discussion}

The results show that the quantity of salt-soluble protein did not increase noticeably when the salt content exceeded $5 \%$. According to the literature [21], when the salt content rises, the elasticity of kamaboko begins to deteriorate, and thus kamaboko cannot be formed. The water molecules are attracted to the salt when the salt content is high, and thus the protein cannot be dissolved because there is no longer enough water. This phenomenon in which the solubility of the protein deteriorates because of a high salt concentration is called salting-out. The fact that the quantity of salt-soluble protein did not increase when the salt content was $10 \%$ is thought to be an indication that salting-out occurred.

According to the elastic modulus results, in the lowmoisture gel, since small amounts of water settled into the protein network, it can be expected that the structure of the network chain was strong. In addition, because the
Table 4 Relationship between the salt concentration and specific surface area of the fish-meat gel

\begin{tabular}{lll}
\hline $\begin{array}{l}\text { Salt } \\
\text { concentration } \\
(\%)\end{array}$ & $\begin{array}{l}\text { Water content at which the } \\
\text { specific surface increased sharply }\end{array}$ & $\begin{array}{l}\text { Change of } \\
\text { specific } \\
\text { surface }\end{array}$ \\
\hline 2.5 & About $77 \%$ & 2 times \\
10 & About $78 \%$ & 1.5 times \\
\hline
\end{tabular}

elasticity of kamaboko is basically due to entropy elasticity $[8,9]$, the volume increases with temperature, and the gel expands and becomes flexible, and thus the temperature influence on the elastic modulus will be greater. On the other hand, for a gel having high moisture content, the distance between the protein molecules is large, and a network structure cannot be sufficiently formed. In other words, because the gel becomes flexible, it is thought that the overall temperature influence on the elastic modulus is small, even at higher temperatures. From the results of the number of network chains, as the water content of the fishmeat gel increased, the number of network chains decreased. These results show a tendency similar to that observed for the experiment on a gel with salt content of $2.5 \%$ [22]. However, a change was recognized when the moisture content was 76-77\%, and at high salt concentration, a change was also seen when the moisture content was high. When the salt content increases, the quantity of dissolved protein increases, which then leads to an increase in the degree of entanglement.

As the water content increased, the average molecular weight between the cross-linking points increased. Kamaboko is a strong gel, because it is supported by a network structure that is formed by a strong combination of S-S and hydrophobic bonds as a result of heating [21], and even if the moisture increases, these covalent bonds cannot be broken easily by heating energy [23-25]; therefore, the network structure also cannot be readily broken. When gelation occurs, the water is maintained in the gaps created by the 3D network structure. It is estimated that the average molecular weight between the cross-linking points increased because the concentration of the protein decreased, then the network grew in size to retain all the water. As a result, we considered that the distance between the cross-linking points increased, and then a relative new network structure formed.

When the moisture increased to $78 \%$, the specific surface area increased by approximately a factor of 1.5 . It is interesting to note that, in the former study [22] on fishmeat protein gel with salt content of $2.5 \%$, as the moisture content of the gel increased from 77 to $79 \%$, the specific surface area increased about 2 times (Table 4). In addition, when the salt content was increased, a sudden increase of the specific surface area also appeared at high moisture. 
From these results, it was concluded that, when the water content exceeds a certain level, the structure of the network chain of the fish-meat protein gel changes.

Kamaboko is regarded as an aggregation of network chains and an aggregate of the protein molecules. If the number of network chains increases and water enters the network, then as a result, it is thought the water hydrates the protein and therefore the hydrophobic bonds disappear [26], and the distance between the cross-linking points increases or the molecular chain is divided. When the salt content is high, the amount of dissolved myofibril protein increases [21], and the cross-linking becomes dense, making it difficult for water to enter the network, and thus the increase in the specific surface area may be limited to a factor of approximately 1.5 .

In addition, beyond a certain moisture content, the specific surface area suddenly increased, because the number of network chains decreased, and the average molecular weight between the cross-linking points increased in the fish-meat gel; this also suggests the occurrence of cleavage of the network chains which are formed through molecular aggregation. It is also possible that hydrophobic interactions [27] between macromolecules that are nonpolar or have weak polarity such as proteins enter into the water solution, contributing to the water structuring. In the gel, it is estimated that there is considerably more of this structured water than can be accounted for by a monolayer of adsorbed water molecules.

Furthermore, the characteristics of the fish-meat gel were compared with gels of AM and M, which make up the network structure of the fish-meat gel, to more scientifically elucidate the changes in the gel constitution with changes in moisture and salt concentration. Independent of whether fish-meat, AM, or M gel was used, the same trends in the molecular weight between the cross-linking points and the specific surface area with increasing moisture content were shown. The specific surface area is thought to reflect the area that exists between the cross-linking points of the gel; therefore, based on the changes in the specific surface area and the molecular weight between the crosslinking points of the gels, it is concluded that the size of the network enlarges, and the network chains are cleaved as the moisture content increases.

To predict the texture of food at any condition of salt concentration and water content, it is important to understand more about the relationship between the function of the gel structure and the rheological parameters, because the rheological properties of food considerably influence its taste.

Open Access This article is distributed under the terms of the Creative Commons Attribution License which permits any use, distribution, and reproduction in any medium, provided the original author(s) and the source are credited.

\section{References}

1. Noguchi S (1992) Science of foods and water (Shyokuhin to mizu no kagaku) (in Japanese). Saiwai Shobo, Tokyo, p 180, 226

2. Goto S, Isemura T (1964) Studies of the hydration and the structure of water and their roles in protein structure. Bull Chem Soc Jpn 37:1693-1697

3. Benjakul S, Visessanguan W, Ishizaki S, Tanaka M (2001) Differences in gelation characteristics of natural actomyosin from two species of bigeye snapper, Priacanthus tayenus and Priacanthus macracanthus. J Food Sci 66:1311-1318

4. Mitchell JR, Ledward D (1985) Functional properties of food macromolecules. Elsevier Applied Science Publishers. London/ New York, pp 64-117

5. Liu R, Zhao S-M, Xiong S-B, Qiu C-G, Xie B-J (2008) Rheological properties of fish actomyosin and pork actomyosin solutions. J Food Eng 85:173-179

6. Comenero JF, Careche M, Carballo J, Cofrades S (1994) Influence of thermal treatment on gelation of actomyosin from different myosystems. J Food Sci 59:211-215

7. Asghar A, Samejima K, Yasui T (1985) Functionality of muscle proteins in gelation mechanisms of structured meat products. Crit Rev Food Sci 22:27-106

8. Takagi I, Simizu W (1972) Application of rubber elasticity theory to Kamaboko. Nippon Suisan Gakkaishi 38:299-303

9. Niwa E, Chen E-S, Kanoh S, Nakayama T (1988) Entropy elasticity of food gels certified by stress-strain relation. Nippon Suisan Gakkaishi 54:245-248

10. Hamada M, Nagai T, Kai N, Tanoue Y (1996) Temperature changes of Kamaboko accompanied by stretching. Fish Sci 62:573-576

11. Yasui T, Ishioroshi M, Nakano H, Samejima K (1979) Changes in shear modulus, ultrastructure, and spin-spin relaxation times of water associated with heat-induced gelation of myosin. J Food Sci 44:1201-1211

12. Damodaran S (1989) Interrelationship of molecular and functional properties of food proteins. In: Kinsella JE et al (eds) Food proteins. The American Oil Chemists' Society, Champaign, pp 21-52

13. Smith DM, Alvarez VB, Morgan RG (1988) A generalized model for predicting heat-induced chicken myofibrillar protein gel strength. J Food Sci 53:359-362

14. Ojima T, Yoshikawa S, Nishita K (1997) Isolation and characterization of myosin from Walleye pollack Suirimi. Fish Sci 63:811-815

15. Lowry OH, Rosebrough NJ, Farr AL, Randall RJ (1951) Protein measurement with the Folin phenol reagent. J Biol Chem 193:265-275

16. Brunauer S, Emmett PH, Teller E (1938) Adsorption of gases in multimolecular layers. J Am Chem Soc 60:309-319

17. Harrington WF, Rodgers ME (1984) Myosin. Annu Rev Biochem 53:35-73

18. Elliott A, Offer G (1978) Shape and flexibility of myosin molecule. J Mol Biol 123:505-555

19. Tanaka F (1994) Introduction to physical polymer science (koubunshi no buturigaku) (in Japanese). Shokabo, Tokyo, pp 91-114

20. Onogi S (1982) Rheology for chemists (kagakusya no tameno reoroji) (in Japanese). Kagakudojin, Kyoto, pp 119-157

21. Okada M (2000) Science of Kamaboko (Kamaboko no kagaku) (in Japanese). Seizando-Shoten, Tokyo, pp 52, 55-56

22. Ogawa $H$ (2005) New information for the gel structure from a dynamic viscoelastic measurement. In: Itoh Y et al (eds) Ashi formation of Kamaboko II (Kamaboko no ashi keisei II) (in Japanese). Kouseisha, Tokyo, pp 64-65 
23. Hamada M, Inamasu Y (1983) Influences of temperature and water content on the viscoelasticity of Kamaboko. Nippon Suisan Gakkaishi 49:1897-1902

24. Hamada M, Inamasu Y (1984) Influences of temperature and starch on the viscoelasticity of Kamaboko. Nippon Suisan Gakkaishi 50:537-540

25. Niwa E, Wang TT, Kanoh S, Nakayama T (1987) Temperature dependence of elasticity of Kamaboko. Nippon Suisan Gakkaishi 53:2255-2257
26. Niwa E (1975) Role of hydrophobic bonding in gelation of fish flesh paste. Nippon Suisan Gakkaishi 41:907-910

27. Niwa E, Matsubara Y, Hamada I (1982) Hydrogen and other polar bonding in fish flesh gel and setting gel. Nippon Suisan Gakkaishi 48:667-670 